\title{
You shall never walk alone: burnout and depression amongst healthcare professionals
}

\author{
Kelvin Lin Chieh $\mathrm{Ng}^{1}$, Chen $\mathrm{Liu}^{2}$ \\ ${ }^{1}$ Institute of Mental Health, Singapore, Singapore; ${ }^{2}$ United Family Hospital, Beijing, China \\ Correspondence to: Kelvin Lin Chieh Ng. Institute of Mental Health, Singapore, Singapore. Email: kelvin_ng@img.com.sg; Chen Liu. United Family \\ Hospital, Beijing, China. Email: chenliu.pumc@gmail.com.
}

Submitted Sep 17, 2021. Accepted for publication Sep 28, 2021.

doi: 10.21037/hbsn-2021-21

View this article at: https://dx.doi.org/10.21037/hbsn-2021-21

\section{Introduction}

There are two stages of tsunami, first is the earthquake in deep sea, followed by hurricane. There are three waves of pandemic, the death toll, economic and social disruption, and a psychological storm that is looming in the distance nowadays. In this time of worldwide COVID-19 pandemic, to date, we have seen over 200 million cases worldwide, and the death toll is in excess of 4 million, and there are various news reports coming in about devastating economic and social situation. Moreover, numerous studies report that the public, as well as the healthcare professionals are at heightened risk mental health problems in the short and longer term from pandemic.

\section{There is no health without mental health}

Definitions of health have changed throughout time, we used to just focus on the biological model, and health then was seen as a state of normal function of the body that could be disrupted from time to time by disease. The World Health Organization in later years, has recognized the importance of linking health to well-being instead, and has defined health as "a state of complete physical, mental and social well-being and not merely the absence of disease and infirmity".

\section{Equality, or rather, inequality between physical and mental illness}

In 2010, it was noted that mental and substance use disorders constituted $10.4 \%$ of the global burden of disease, and were the leading cause of years lived with disability amongst all disease groups (1). In 2011, the World Economic Forum acknowledged that there are "hidden costs" of diseases (US\$1.7 trillion), which are much higher than the direct costs (2), that has made mental disorders accounted for more economic costs than chronic physical diseases such as cancer or diabetes, yet, the treatment gap for mental disorders is higher than for any other health sector. Thus, the system sees the increasing importance of mental and social well-being to be considered as an integral part of health, but strives to attain and achieve on top of just physical health.

\section{We are not immune}

Depression is a common illness worldwide, with more than 264 million people affected and this is estimated to be equivalent to $3.4 \%$ of the world's population (3). There are several robust studies which have suggested that the rates of depression are higher in medical students and residents $(15-30 \%)$ as compared to the general population, and this pattern seems to persist even despite the advancement of their professional career (4).

We have to understand that physicians are not only not immune to depression, but we possess certain psychological vulnerabilities that make us more susceptible to depression. As doctors, we are often subjected to punishing work schedules, administrative procedures, teaching and training and research. We often have insufficient sleep, sometimes sacrificing our meals and toilet breaks, even at home, we are hardly getting rest without worrying about work. Junior doctors have to endure physical hardship of doing scud work and being on-call and passing the exams, with the hope that 
life will be better when they become specialists. Ironically, the experts in the field of practice find themselves envying the juniors for their freedom: specialist who is the only one able to perform a particular surgical procedure, and thus one becomes a slave to one's expertise and efficiency.

\section{Professionalism and perfectionism}

We know that the medical profession is not only subjected to the laws of the land wherewith we practice medicine, but we are also held accountable to an even higher standard of professionalism and clinical ethics. The tabloids and newspapers are quick to emblazon front page headlines of this doctor being found out of having an affair or guilty of some other sordid or sensational crime, but we certainly do not see such similar treatment if the perpetrator is an engineer or architect.

Apart from being held accountable to the legal system, the clinical code of ethics and professionalism, many of us are perhaps most bound by ourselves. Many doctors possess certain qualities, like ambition and drive, setting high standards for themselves, that make us to be the best that we can be, to push ourselves to our absolute peak and to challenge our limits, and these qualities drive us to become excellent doctors. Unfortunately, it is proven that those personality traits like perfectionism and self-criticism are common among physicians, which increase the risk of depression (5). We enter into Medicine to help people and save lives, but more often than not, sadly, we face failure and loss. When facing such "failure", it is the same qualities that we value may lead us to self-doubt and worse, self-criticism and self-blame, personal responsibility overshadows all else and we are not even able to consider whether there were other mitigating factors or extenuating circumstances that could have contributed to the failure, and this can be extremely damaging to one's self-esteem and pride.

\section{Physician, heal thyself! Or should we?}

There is always the danger that we as doctor face, when it comes to caring for ourselves. Many of us are first blind to what ails us. Just like we are not able to be objective when it comes to treating our family and loved ones, either fearing to consider more serious diagnoses because we do not wish for such a condition to be present, or else we are not able to distance ourselves to our loved ones when it is required to administer treatment, like operating on their bodies, so it is when it comes to ourselves. Very often, we ignore signs and symptoms, deceiving ourselves with facts and figures in the hope that it would go away, and end up seeking for help only when it is too late.

Even when we have decided that we can no longer ignore the problem, seldom do we seek formal consultation and treatment for our ailments, especially when it is mental health related. I recall there are times when I have been engaged in a "corridor consultation" with my other colleagues, asking on behalf of their "friend or patient", informally of course, about self-assessment tools, or other conversations on WeChat or WhatsApp about what is the treatment for Depression, and we know that they might actually be seeking these answers for themselves. Very often, we shy away from exposing ourselves or showing weakness to our fellow colleagues, and try to administer treatment for ourselves, in the hope of getting better without a formal medical review. I guess we can treat ourselves for minor ailments like coughs and colds, but the treatment of Depression and other mental illnesses are not so straightforward, as the illness impairs one's judgement, motivation and insight, and self-treatment can sometimes lead to more harm than good.

\section{Stigma, stigma amongst healthcare professionals and self-stigma}

WHO defined stigma as "a mark of shame, disgrace or disapproval that results in an individual being rejected, discriminated against and excluded from participating in a number of different areas of society". Depression, and indeed, mental illness as a whole, has a very great stigma associated with it, and we know that stigmatization of persons with mental illness is a major barrier in the treatment process. The doctors may exhibit stigma towards mental illness in one or more of the following ways: they may be disinterested in the patient's mental health history, become therapeutic pessimism, structural discrimination related to poor quality psychiatric treatment or rehabilitation measures and sharing insufficient information on diagnosis (6).

With such stigma associated with mental illness, it is thus not surprising that this stigma has also impacted healthcare professionals with regards to willingness to seek help for a mental health problem, for fear of being perceived as less competent, less productive and unsafe to work with even (7). There is the added burden or worry that the healthcare 
institution may, either real or perceived, prejudice against those medical practitioners with mental health issues, and affect their career opportunities and further advancement, even though their mental health issue may not affect their ability to perform at work.

Perhaps more significant and damaging is that of selfstigma. Self-stigma involves emotionally or cognitively absorbing the negative beliefs about the self, largely based on shame, accepting mental illness stereotypes, alienating oneself from others, and feeling a sense of disempowerment (8). We may feel embarrassed, or worse shame, to admit that we may be having a mental health issue like depression, either to another medical professional, or even ourselves. This self-stigma thus robs us of seeking professional help, and a chance of getting better.

\section{Conclusions}

\section{Not pride of knowledge, but humility of wisdom}

The school motto of "Not Pride of Knowledge, but Humility of Wisdom" was introduced to me when I first entered medical school. In simple terms, it meant that as medical students, as we progressed in our medical studies and gained knowledge, we should always remain humble. However, as I write these closing words, I am reminded again of my alma mater's motto, but applied in a different way. How often do we advise, encourage and sometimes admonish our patients to take care of themselves, to eat and sleep properly, to rest, to have self-care whenever they are sick, and ignore these words when it comes to ourselves? We have the knowledge, but it is our pride that keeps us from following our own advice. Perhaps we all need to be learn humility, to understand that we are but human, with all our human fragilities and weaknesses that make us prone to disease, physical or mental, and then only will we pay heed to our knowledge, and finally gain wisdom.

\section{Acknowledgments}

Funding: None.

\section{Footnote}

Provenance and Peer Review: This article was commissioned by the editorial office of Hepatobiliary Surgery and Nutrition. The article did not undergo external peer review.
Conflicts of Interest: Both authors have completed the ICMJE uniform disclosure form (available at https://hbsn. amegroups.com/article/view/10.21037/hbsn-2021-21/coif). The authors have no conflicts of interest to declare.

Ethical Statement: The authors are accountable for all aspects of the work in ensuring that questions related to the accuracy or integrity of any part of the work are appropriately investigated and resolved.

Open Access Statement: This is an Open Access article distributed in accordance with the Creative Commons Attribution-NonCommercial-NoDerivs 4.0 International License (CC BY-NC-ND 4.0), which permits the noncommercial replication and distribution of the article with the strict proviso that no changes or edits are made and the original work is properly cited (including links to both the formal publication through the relevant DOI and the license). See: https://creativecommons.org/licenses/by-nc-nd/4.0/.

\section{References}

1. Whiteford HA, Degenhardt L, Rehm J, et al. Global burden of disease attributable to mental and substance use disorders: findings from the Global Burden of Disease Study 2010. Lancet 2013;382:1575-86.

2. Bloom DE, Cafiero ET, Jané-Llopis E, et al. The global economic burden of noncommunicable diseases. Geneva: World Economic Forum, 2011.

3. GBD 2017 Disease and Injury Incidence and Prevalence Collaborators. Global, regional, and national incidence, prevalence, and years lived with disability for 354 diseases and injuries for 195 countries and territories, 1990-2017: a systematic analysis for the Global Burden of Disease Study 2017. Lancet. 2018;392:1789-858. Erratum in: Lancet 2019;393:e44.

4. Tyssen R, Vaglum P, Grønvold NT, et al. Suicidal ideation among medical students and young physicians: a nationwide and prospective study of prevalence and predictors. J Affect Disord 2001;64:69-79.

5. Vaillant GE, Sobowale NC, McArthur C. Some psychological vulnerabilities of physicians. N Engl J Med 1972;287:372-5.

6. Heim E, Kohrt BA, Koschorke M, et al. Reducing mental health-related stigma in primary healthcare settings in low- and middle-income countries: a systematic review. 
Epidemiol Psychiatr Sci 2018;29:e3.

7. Knaak S, Mantler E, Szeto A. Mental illness-related stigma in healthcare: Barriers to access and care and evidencebased solutions. Healthc Manage Forum 2017;30:111-6.

Cite this article as: $\mathrm{Ng} \mathrm{KLC,} \mathrm{Liu} \mathrm{C.} \mathrm{You} \mathrm{shall} \mathrm{never} \mathrm{walk}$ alone: burnout and depression amongst healthcare professionals. HepatoBiliary Surg Nutr 2021;10(5):678-681. doi: 10.21037/ hbsn-2021-21
8. Henderson C, Noblett J, Parke H, et al. Mental healthrelated stigma in health care and mental health-care settings. Lancet Psychiatry 2014;1:467-82. 